\title{
Is It Prudent Not to Learn from Our Living Legends?
}

\author{
Neha Chauhan ${ }^{1}$ \\ ${ }^{1}$ Department of Plastic Surgery, Chinmaya Mission Hospital, \\ Bangalore, India
}

Indian J Plast Surg 2019;52:261-261

\section{Dear Sir,}

The knowledge of plastic surgery is growing by leaps and bounds with every passing day. We have come a long way from Sushruta to Gillies to the current generation of plastic surgeons. It cannot be emphasized better by anything than by Isaac Newton's quote of 1675 (where he states that "If I have seen further it is by standing on the shoulders of Giants") that where we are today is because of the works of our predecessors. The author has observed that the Indian Journal of Plastic Surgery honors such giants in the "Icon of the issue section" where either a student or a close relative of the masters who are no longer with us narrates his/her life, principles, and contributions to plastic surgery. Besides this the Indian Journal of Plastic Surgery also publishes obituaries of prominent contributors to the field. In author's opinion, since these are biographies written by someone else, there are bound to be some aspects which cannot be clearly brought out as the person about whom it is written is no longer with us. There is also a definite possibility that the analysis and perspective of the biographer and that of about whom it is written could have been entirely different!

Hence the author proposes that the Indian Journal of Plastic Surgery should, besides these biographies, publish interviews of the "living legends" of plastic surgery who are available with us for a dialogue and whose perspective and lives could be brought out directly from the legends themselves. Such interviews would give us an accurate account of not just the accomplishments but also of lives, struggles, mistakes, and regrets, if any, of those who have contributed significantly to plastic surgery. They would prove to be a huge source of learning to the younger generations of plastic surgeons and inspire the promising surgery
Address for correspondence Neha Chauhan, MCh (Plastic Surgery), Department of Plastic Surgery, Chinmaya Mission Hospital, CMH Road, Indiranagar, Bangalore, Karnataka, India (e-mail: drnehac@gmail.com).

postgraduates to take up plastic surgery as superspecialty. It will also make for an interesting read for nonplastic surgeons (to whom the usual technical articles in plastic surgery are of no interest) and promote our specialty to the colleagues in other specialties. In account of any questions being missed by the interviewer (a possible human error ...), it can be asked by the readers as a letter to the editor or be addressed directly to the legend and published in the next issue of Indian Journal of Plastic Surgery. Such interviews can be preserved for posterity and eventually replace (once we have honored our past masters and regularly publish the interviews of the living legends) the current format. After all, one does not become an icon only after passing away! To the author the idea that a certain person's contributions seem significant enough to be published only after he/she is no longer with us seems like a delayed attempt at reconstruction. Why not preserve their lives and learn from the masters when they are amongst us? Their lives, work, and contributions should be recognized right now when they are amongst us to guide us and show us that beacon of light as a first-hand account.

Plastic surgery is all about being able to "mold into the desired form" for the betterment of an individual and the author feels that it is the correct time to mold the format of the Indian Journal of Plastic Surgery to include interviews of living legends whose exciting lives can be inspirational to many.

\section{Conflicts of Interest and Funding}

None.

Presentation at Meeting

None.
DOI https://doi.org/

10.1055/s-0039-1695801

ISSN 0970-0358.
(C2019 Association of Plastic Surgeons of India
License terms

()(1) $\ominus \circledast$ 